\title{
Glossing Over: How Magazine Fact Checkers Use Conditional Self-Presentation to Straddle Glamour and Dreariness in Their Work
}

\author{
Sandra E. Spataro \\ Northern Kentucky University \\ Lisa E. Cohen \\ McGill University
}

In this paper, we introduce the concept of Glossy Work, work that has a glamorous patina but that is actually mundane and unfulfilling. We studied magazine fact checkers, who exemplify Glossy Work, specifically examining how they balance these discrepant aspects of the job in presenting their work to others. We found that fact checkers use conditional presentation to modulate their portrayal of the work according to audience members' knowledge of their job's secret taint and the nature of presenter's relationship to that audience. Presentations ranged from full disclosure to deliberate attempts to reframe the presentation to unfettered job enhancement.

Keywords: self-enhancement, presentation, self-verification

\section{INTRODUCTION}

Because you're affiliated with the magazine people think you're a strange type of royalty no matter how you're affiliated.

You're almost embarrassed to say you're a fact checker to people in the industry cause immediately they shut you off... and you just say, "That's not what I am. That's what I do. That's what I do to pay the rent."

These quotes from two individuals working as magazine fact checkers illustrate a conflict inherent to their jobs and to the jobs that many people hold. On one side, the job comes with high status affiliations that many see as glamorous. On the other, the tasks associated with the job are mundane with little intrinsic value. And many industry insiders hold the job itself, and job holders, in low esteem. Because of this conflict, those who hold the job face multiple dilemmas when they present themselves and their job to various audiences. Not only is the job a mixture of good and bad, knowledge of the job's essence is distributed unevenly across audiences.

The particular conflict between a façade of glamour and day-to-day drudgery is the central tenet of a type of work which we call Glossy Work. We define Glossy Work as work that is experienced by those 
doing it as mundane and unfulfilling but that is performed in a context that provides far more glamour than the nature of the work would imply. Glossy Work jobs would score low in terms of their intrinsic ability to motivate and create job satisfaction (Van Yperen, Wortler, \& De Jonge, 2016; Hackman \& Oldham, 1975). They do not inherently provide dignity to their incumbents (McGregor, 2017; Hodson, 2001). However, they often emerge in industries or around products and services that are luxuries or are viewed as glamorous. For example, in the film industry the positions of production assistants and script supervisors would be Glossy Work.

Glossy Work has much in common with other seemingly bad jobs that have been described in the literature, from janitors and factory workers to doctors and bankers in ethically suspect institutions. However, it is also distinct from this previously researched work. For example, Glossy Work lacks the moral taint of Dirty Work (Ashforth \& Kreiner, 1999; Ashforth, Kreiner, Clark, \& Fugate, 2007; Hughes, 1958,1962 ) and instead is characterized by a positive view from outsiders.

This discrepancy in Glossy Work presents multiple challenges for those who do it. Inconsistency in one's self-concept is inherently uncomfortable (Church, Katigbak, \& Reyes, 2014; Festinger, 1954; Heider, 1958), even beyond the discomfort of being in a mundane or unfulfilling job. This is acutely the case when the discrepant aspects of the self carry different status values (Milner, et al, 2017; Starr, 1977) or when the discrepancy is between aspects of one's image at work (Vough, Cardador, Bednar, Dane, \& Pratt, 2013), both of which are true with Glossy Work. Previous research shows that when aspects within one's self-concept are incongruent, an individual may experience difficulties trying to reconcile the conflicting expectations (Starr, 1977) that might not be reconciled simply by embracing the more positive identity. Inconsistent images of primary aspects of the self have been linked empirically to negative or unstable self-images (Fenchel, Monderer, \& Hartley, 1951), symptoms of stress (Honjo, et al, 2014; Jackson, 1962), and even mental disorders (Milner, et al, 2017; Dunham, Phillilps, \& Srinivasan, 1966).

Beyond the general discomforts of incongruence among aspects of the self, the discrepancies that characterize Glossy Work create challenges for the construction of identity and associated images. Work based identities are important. The social identities associated with both work and the workplace contribute to one's overall self-concept (Ashforth, 2001; Mael \& Ashforth, 1992; Tajfel \& Turner, 1986). Identification with a positively viewed organization or job has been associated with self-esteem and distinctiveness, whereas, association with negatively valenced jobs or organizations threatens overall well-being (Ashforth \& Kreiner, 1999; Elsbach \& Bhattacharya, 2001). Those doing Glossy Work enjoy positive organizational identity resources from the prestige of the external identity of the organizations that employ them (Ashforth \& Mael, 1989; Dutton, Dukerich, \& Harquail, 1994), and, at the same time, a threat to their positive identity from low occupational prestige associated with the work itself (Treiman, 1977). The discrepant sides of Glossy Work jobs also have implications for image management (Roberts, 2005; Vough, et al., 2013). The external image individuals cultivate and project can determine their social approval, power, and overall well-being (Baumeister, 1982; Schlenker, 2003). The conflict between the positive and negative identity and image resources inherent in Glossy Work raises the question of how workers in these jobs organize and manage their work-based self-concept. Thus, in this paper we seek to understand how those engaged in Glossy Work straddle these discrepant sides of their vocation for themselves and for various audiences.

Much of the "work" of coming to terms with the job is done through presentation of the job to the self and to others. Job holders can provide narrative descriptions of their work to others, and they can present their work by performing it. Through their actions and interactions job holders define themselves to various audiences. Social interaction at work is a platform for impression formation, identity management, and role negotiation (Goffman, 1956; Meyerson, 2001). We can thus glean self-presentation both from direct narration and from interpretations of behavior.

Job presentations serve multiple functions for multiple audiences (Fine, 1996; Goffman, 1956; Ibarra $\&$ Barbulescu, 2010). Divergent motivations in different presentations can influence how objectively the job is presented to these audiences. Do they describe what they really do? Do they act in a way that is consistent with their formally defined job? Given the discrepant nature of Glossy Work, two motives are 
of particular interest: the motive to feel better about oneself and the motive to be fully seen and understood.

In this paper, we examine the presentation of work in a sample of people employed as magazine fact checkers, a line of work that typifies our definition of Glossy Work, to understand whether and how presentations of their work reflect these motivations and how such motivations play out differently across different types of audiences. Our findings indicate a model of conditional self-presentation that is contingent on the audience for the presentation, consistent with the extant literature, but which is more complex and more nuanced than simply segregating differently motivated presentations to different audiences. In fact, Glossy Work job holders do not seem to compartmentalize the discrepant aspects of their job, focusing on the positive part with one audience and the negative with a different audience. Instead, their job presentations seem to hold fast to the discrepancy where such full disclosure of both the bad and the good is "safe," and their presentations tack away from tainted role-based images and toward more personal characteristics when there will be ongoing interdependence with an audience they cannot fool.

\section{Self-enhancement and Self-verification Motivations}

In presenting their work, people are conveying who they are and how they should be taken, both to others and to themselves (Fine, 1996). Such narratives offer opportunity to engage the audience in whatever reality about the job best serves the presenter's purpose. Two primary motivations that likely shape presentations of work are self-enhancement (Allport, 1937; Taylor \& Brown, 1988; Tesser, 1988) and self-verification (Swann, 1983, 1990).

Self-enhancement tendencies reflect individuals' motivations to make themselves look better and to create positive esteem, even when it leads the presenter to deviate from reality (Crowne \& Marlowe, 1964). If the literature on the presentation of work has pointed to a general tendency, it is that people enhance their work when they describe it, a tendency that is consistent with research on self-enhancement (Taylor \& Brown, 1988; Tesser, 1988). For example, rather than say "I sell skillets," a skillet salesperson says "I am in sales" or "I am in promotions" (Fine, 1996). Restaurant workers make upward analogies to artists (Fine, 1996). Zookeepers talk about their work as a calling (Bunderson \& Thompson, 2009). Janitors lay claim to various aspects of professionalism in their descriptions of interactions with tenants (Gold, 1952). This motivation to enhance the identity associated with one's work is pervasive (Tajfel \& Turner, 1986), suggesting that those engaged in Glossy Work would draw heavily on the glossy aspects of their work when presenting it to others and find ways to use these aspects to elevate the job as a whole.

Nonetheless, the motivation to self-verify is also very compelling; individuals seek and benefit from a sense of consistency in their self-concept, even when the subject of the consistency is negative (Swann, 1983, 1990). There is important emotional benefit to being accurately recognized and known (Goffman, 1967) and seen as authentic (Peterson, 2005). However, the literature on job presentation is less informative about whether and how holders of unsatisfying jobs would bring aspects of the job that are less favorable into their descriptions. Though motivations for feedback that is both self-enhancing, when positive, and self-verifying, when less favorable but true, are well documented (Swann, 1990), voluntary presentations of work are more often depicted as enhancing than accurate. Though they may be accurate, downward comparisons and denigrating descriptions are relatively less common in the literature.

It is important to note that self-enhancement and self-verification motivations are not mutually exclusive. Indeed, they have been shown to simultaneously drive behavior in individuals (Swann, Pelham, \& Krull, 1989), such that positive, enhancing feedback is generally preferred for the positive aspects of the subject and negative, verifying feedback is preferred for the opposite. The question, as it relates to Glossy Work, is whether and how presentations of glossy work reflect these motivations.

\section{Audiences for Glossy Work Job Presentations}

In addition to reflecting a job incumbent's inward reflections on the job and what it means to their self-concept, presentations of one's work help form impressions that influence how various audiences see the work and how they see those doing the work (Goffman, 1956). Glossy Work's distinguishing 
characteristic implies that there are insiders to the job's "secret" negativities and that there are outsiders who only see the glamour (White, Stackhouse, \& Argo, 2018; Schlenker, 1975). While the insiders are a "back-region" audience with whom they can relax, the outsiders are a "front-region" audience with whom they must be on guard (Dick, 2005; Goffman, 1956). Still, "insider" status is not the only feature that distinguishes audience types for Glossy Workers. Frequency and nature of interaction between the job holder and the audience member are also likely meaningful differences among those hearing job presentations (Schlenker \& Leary, 1982). Various audiences along these dimensions offer different potential opportunities for Glossy Work job holders to form different impressions and lay down different expectations for responses from the audience. We therefore expect Glossy Work job occupants to vary their presentations according to audience knowledge of the job and nature of interaction with the audience though it is less clear exactly how.

\section{METHODS}

We used qualitative methods to examine how people who do glossy work present their work to various audiences. This approach is appropriate for a research question that, like ours, is exploratory (Dick, 2005; Edmondson \& McManus, 2007). Our informants are fact checkers employed by a glossy magazine. As the examples at the beginning of this paper showed, fact checking exemplifies the conflict central to Glossy Work.

\section{The Setting: Magazine Fact Checking}

Fact checkers are employed by many high status, glossy magazines. The fact checkers' job occupies a place low in the hierarchy within the magazines and within the broader field of journalism. Their names appear low on magazine mastheads, after proofreaders and sometimes after editorial assistants and their salaries are low compared to those who occupy the higher masthead positions.

While the formal job title varies from magazine to magazine - assistant editor, research editor, research associate, research assistant, researcher, editorial assistant - in common parlance, the people performing the job are called fact checkers. Across these titles, the job responsibilities are essentially the same: to ensure the factual accuracy of articles (Cohen \& Staw, 1998). The fact checkers interviewed for this study all report to the head of their fact checking department who in turn reports to the managing editor. The department head assigns them to articles, reviews their work, and offers assistance. On a dayto-day basis, however, they performed tasks that served story editors and writers directly, rather than with or through their manager.

\section{Interviews with Fact Checkers}

The second author conducted interviews with twelve fact checkers. This included the entire permanent and freelance fact checking staff of one publication, which we call Prestige, and a snowball sample of three fact checkers from two additional publications. Two of these had experience at Prestige. See Table 1 for a full list and description of individuals interviewed. While this is a small number of interviews, it is enough to allow for the development of theory about how individuals present their work to different audiences, as well as comparison across individuals. Each checker we interviewed described multiple occasions in which they presented themselves to multiple audiences. In these interviews, we used a critical incidents approach where subjects were asked to describe articles that they had fact checked, including a recent example, a difficult example, and an ideal example. Based on this we have over 40 descriptions of work episodes, each of which involved presentation of the work.

Interviews were open-ended, with questions focused on how fact checkers got the job done and how they experienced the job. In addition, subjects were asked about the support they received at work, about what things might make their work difficult and about how they might describe their work to others. 
TABLE 1

\section{LIST OF FACT CHECKERS INTERVIEWED}

\begin{tabular}{|c|c|c|l|}
\hline Position & Publication & Age & \multicolumn{1}{|c|}{ Education } \\
\hline Head & Prestige & 38 & $\begin{array}{l}\text { BA in history, languages and the arts from liberal arts } \\
\text { college }\end{array}$ \\
\hline $\begin{array}{c}\text { Deputy } \\
\text { Research Editor }\end{array}$ & Prestige & 34 & BA in history from a liberal arts college \\
\hline Freelance & Prestige & 38 & Masters in journalism from a top program \\
\hline Staff & Prestige & 26 & BA from an Ivy League university \\
\hline Freelancer & Prestige & 29 & Studied in Paris \\
\hline Freelancer & Prestige & $40+$ & BA in English from a liberal arts college \\
\hline Staff & Prestige & 30 & $\begin{array}{l}\text { BA from an Ivy League university; } \\
\text { Masters in dramatic writing }\end{array}$ \\
\hline Staff & Prestige & 26 & BA in English literature from Ivy League university \\
\hline Freelancer & Prestige & 31 & $\begin{array}{l}\text { BA in Russian studies from a liberal arts school; Masters } \\
\text { in architecture }\end{array}$ \\
\hline Head & $\begin{array}{c}\text { Former } \\
\text { Prestige } \\
\text { Staffer }\end{array}$ & 32 & BA in English from a top tier state university \\
\hline Freelancer & Elite & 29 & BA in psychology from a liberal arts college \\
\hline Staff & Elite & 26 & BA in comp literature from an Ivy League university \\
\hline
\end{tabular}

\section{The Interviewer as Confidant}

The interviewer had been a fact checker for five years on staff and as a freelancer for magazines similar to those for which the fact checkers worked and revealed this to all respondents. This insider relationship allowed the interviewer to play the role of confidant: someone whose perceptions had little consequence for the fact checkers since these interviews were not a basis for ongoing interaction and someone who was known to be aware of the job's "secrets." In analyzing the data, we saw that the presentations made to this confidant differed in nature from those intended for other audiences. That the fact checkers spoke differently to this sort of confidant is exactly what allowed us to examine our research question.

There is a risk that this insider status and the knowledge that comes with it influenced how the data were collected and analyzed, and what respondents revealed (Anteby, 2013; Elias, 1956). We took precautions to avoid biases that have been described as risks when data is collected by an insider and took corrective measures when we saw problems (Anteby, 2013; Elias, 1956). First, the interview questions were developed by the second author (who was the interviewer) and another co-author (not involved in this project) with no prior knowledge of fact checking. This naïve co-author reduced the likelihood of taking certain knowledge for granted. Further, all transcripts were reviewed by the interviewer, the coauthor from the previous project, and the first author of this paper, who also had no prior knowledge of fact checking. Both authors on this project were involved in the coding of the data into categories. The first author actively challenged the insider-interviewer about whether certain conclusions could be made based on the data throughout the analysis process.

Another concern was that fact checkers may have been providing what they believed to be socially acceptable answers in these circumstances: for instance, saying that they want to leave may seem to be the right thing to say to a person who left. With this in mind, we looked at whether there was a consistent pattern in areas where we thought this might be an issue. There was considerable variability in responses, enough to reduce our concerns that these were pre-programmed answers.

An alternative approach that might have mitigated some of these concerns would have been to have the interviews conducted by a complete outsider. However, it is not clear that an outsider would have 
been treated as a confidant. It seems likely that the outsider interviewer would have heard a more sanitized description of the job, similar to what the fact checkers provide to other outsiders.

\begin{abstract}
ANALYSIS
Interviews were transcribed and then coded into five broad categories: background information, descriptions of the job and work, descriptions of how fact checkers do the work, characteristics fact checkers like and disliked about the job, and outcomes related to the work. Items in each category were then sorted into many finer grained categories. We then looked at audience characteristics and identified three primary audiences: the interviewer (an insider to the job's "secret" negative realities and a one-time interaction partner for the fact checkers); the writers (partial insiders to the job's secret and an audience with whom they had ongoing, interdependent interaction); and complete outsiders (who were not in on the secret and with whom the fact checkers only expected to interact once). Next, we sorted the various items categorized by audience type and sought to understand more about what was in the items presented to each of the audiences and how each item related to the two opposing faces of the job. We identified subcategories within several of these. We considered to what degree each incorporated both the good and bad aspects of the job and whether and how these activities might reflect self-enhancement or self-verification motives.
\end{abstract}

\title{
Findings: Conditional Self-presentation
}

We discuss presentations made to three different audiences - the confidant, semi-insiders, and the uninitiated -- and how each of these relates to our expectations. At the beginning, we expected fact checkers would seek to enhance or elevate the job with all audiences and do so more with audiences where they believed they would be more convincing. Our expectations about how this would vary across audiences were less well developed going in. We expected that this enhancement would be balanced to a degree by a tendency toward self-verification but that self-verification would be less of a force with audiences from whom they could keep the job's "secret" secret.

\section{Presentations to the Confidant}

Job presentations to the confidant fell into three categories: those directly addressing the negative aspects of the job; those building on the more positive, glossy, aspects of the job; and those that created distance between job holder and the job. Fact checkers spoke unguardedly to the confidant about the things below the job's surface that they did not like; they did not treat the job's secret as one at all. At the same time, however, they also described glossy aspects of the job. In addition, they spoke freely about their relationship to the work, providing various justifications for why they were doing the job. They accepted their role within the job, and, at the same time, they created distance between themselves and the job.

\section{Beneath the Gloss: Challenges and Negative Circumstances}

In presenting their jobs to the confidant, every fact checker talked at length about the many things that they did not like about the job, that would make the job seem less than desirable, and that created challenges for them. The nature of the work itself - the tasks that made up the job - figured prominently in how fact checkers talked about the downsides of their job. They described the work as routine and repetitive, referring to the magazine as "very much an assembly line place." One checker compared the work to something that a monkey could do:

So checking all the names and what was this guy's wife's name and who's his wife. She's not in Who's Who. They're all dead. All the friends are dead. And it's just a pain in the ass. Technically it's something that a monkey can do but you've got to pay attention to it.

We include additional quotations illustrating this tendency and other negative descriptions in Table 2. 
TABLE 2

NEGATIVE ASPECTS OF THE JOB

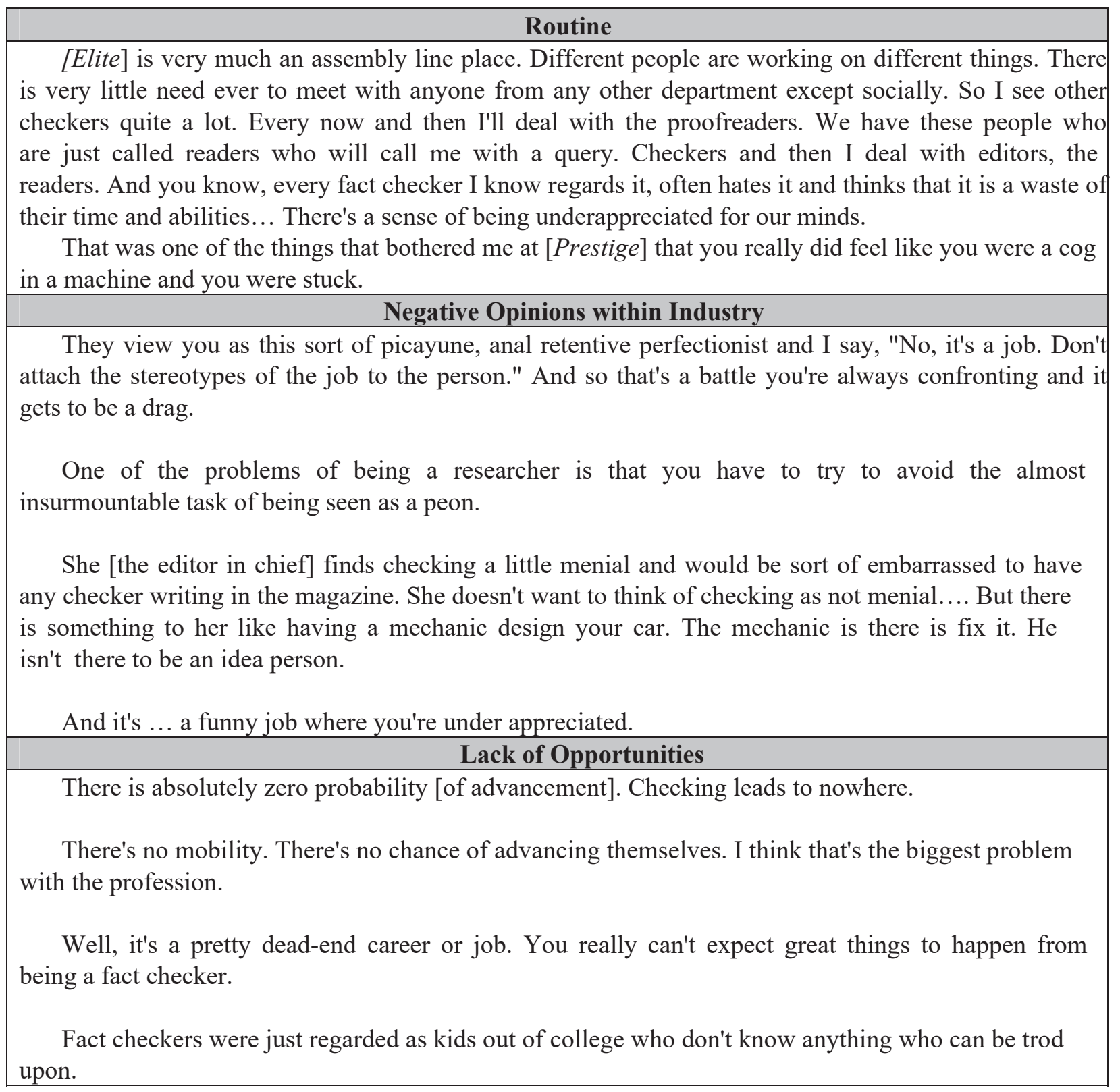

The negative descriptions of the job extended to aspects beyond the tasks performed. Many fact checkers also commented on the negative views held by others within the industry and how this affected their self-esteem, offering analogies to the work as being like that of a clean-up crew, as in this quotation:

Cause it's behind the scenes work. Because it's like women's work. We clean up. We deal with the dirty aspects of a story and make it clean. And traditionally that role, because it's "not creative" and this is a creative medium and anything not creative is less valued overtly even though it is absolutely necessary, essential and any major or minor magazine can't function without it. It's devalued cause it's not creative. 
Many other challenges discussed were structural in nature - both in terms of the immediate job and how it fit into any system of career progression. Checkers explained a true lack of job security, a sense of being entirely expendable: "John Ford made a movie called They Were Expendable... and we are!" And they noted lack of career path stemming from the fact checking job: "The doors are entirely smacked shut." Their impressions about mobility chances were consistent with reality. In the fifteen years after Prestige was created, only two fact checkers moved on to other positions at the magazine.

\section{Putting on the Gloss}

Fact checkers also described positive aspects of the job, almost all relating to factors other than the tasks that they performed. The checkers had a repertoire of ways they glossed up the job, including taking pride in the skills required to do the job:

[Another fact checker] had this little motto that I used to have on my board: "Fact checking is a unique blend of highly articulated intelligence and a sense of craven humility."

Most checkers highlighted their own unique skills by emphasizing the importance of having the right personality, a sense of humor and humility, and being able to deal with difficult personalities through patience, persistence, and professionalism, as illustrated here:

The personality business that it's beyond just looking up in a book and I don't know that you can teach that. I think the reporting aspect and psychological aspect and manipulative aspect you have to-I think you can learn some of that but I think some of it's not teachable.

Further examples of these types of descriptions and others are included in Table 3.

\section{TABLE 3 \\ POSITIVE ASPECTS OF THE WORK}

\section{Skills Used in the Job}

He's--again intelligence--but just a really really nice guy. Hugely funny, very dry sense of humor and sees personalities, in a sense a lot of the situations if you understand people quickly you know, he keys in right away and he knows

Because I realized that the job is part of is more part of an organic flowing process as opposed to just being a stickler...because there's a certain amount of P.R. involved in being a fact checker....So it's the technical as well as the more social part of it.

Being able to ask difficult questions is a good. And being able to phrase difficult questions in a tactful way.

What makes [a fact checker] good is his incredible ego and his abrasiveness and his unwillingness to take any shit no matter who he's talking to.

\section{Learning from the Work}

It's a great way to learn the nuts and bolts of reporting and where to get information. You see a ton of bad writing come across your desk every day. You see a ton of good writing come across your desk. You see editors shape stories. If the checker is really adroit and pays attention, there's no better learning ground.

You can't but help but pick up good journalistic skills by fact checking because you see how a piece is put together from beginning to end, especially with some pieces where you have to help report them. 
I've learned a whole hell of a lot about the craft of writing and how you report and how you don't get things wrong: It's given me confidence about writing.

It also teaches you, I think, certain skills that are very desirable if you want to be a writer.

\section{Intellectual Environment}

You're surrounded by over intelligent people who have all sorts of real world experiences. At the big fact checking departments at magazines like Prestige and Elite, the head of fact checking tries to bring in people from all kinds of walks of life. Artistic people. Historic people. Travel. Music...

Because it's the ultimate graduate school. It's such a learning process. You're more less forced to become an expert upon every subject that you've ever worked on and I've worked here for over five years and I've done everything from the car column to major political pieces to arts to wine column everything I've more less been forced to become an expert on almost every subject the magazine has covered.

You get to read books that you've wouldn't of read before you get to talk to people that are completely fascinating stimulating and then socially you wind up becoming part of a world that is very intriguing and also sometimes very challenging and a lot of who I've become as a human being as a person is a result of the education I've gotten here.

\section{High Status Associations}

It lets me fool myself into thinking that I'm doing something, somehow worthy cause it has to do with writing.

I like the feeling of being in the know about what's going into a magazine before it hits the newsstands. I think that I'm somehow special because I know that cause I'm on the inside at Prestige.

What appealed to me first about it was that I was working for Prestige magazine...

\section{The Importance of the Role}

We're the standards and practices department and whether we're doing the actual reporting because the writer did it badly and you have to follow it up. It's a form of reporting.

I'm trying to make sure that the magazine is accurate and not misleading to the reader. That it is fair to the sources. That it's still a good read. And to protect the magazine from nuisance suits and more serious legal suits.

Well if you're writing serious non-fiction pieces, it's indispensable. Even for like a fashion magazine, it's embarrassing to dribble with dumb things. Everybody makes dumb mistakes. Even inputting you can make small errors.

Just making sure that they're legal and factual and they are correct a piece cause the magazine I guess that's the only reason why we're hired that's the only reason why there's a research staff the reason why such a large research staff is cause the magazine priorities and they need to have legal factual things correct in every article.

We have the biggest chunk of work to do to fit into the entire schedule. . . Nothing goes forward without the research sign off at each stage. So we can really muck up the works. It has to be accounted for in the planning of the production process. It's a big factor.

\section{Making their own Contributions}

I feel very good sometimes when I make positive contribution to a story where I find something out the writer hasn't known I'm not talking about mistakes I'm talking about information that the writer uses.

What I like to have is I like to go through a writer's interview and find a quote that they overlooked and tell them about it and that they like it and they are happy that I brought it up. That it helps the story. That's the kind of success I like

I'd also like to talk about another story that I thought was a positive experience, as positive as fact checking gets cause it involved reporting and writing with an English writer who didn't know a thing 
about reporting, but it was a crime story which is great for me. I got to talk to cops and find out stuff and put it in the story. So I felt like I was actually doing something.

The best part of this job--I'm tempted to say the only acceptable part of the job but it's almost fun is the reporting. You find things out for people and provide the information. You know find a quote they didn't see in a transcript they didn't write down

Anytime I can report. I was talking about that story by a British writer... He was using all British tabloid sources which are just atrocious for accuracy and I had to reconstruct a major part of the reporting through daily conversations with the London police who were working on the case and other people. I had to establish rapport with the police. We fixed the story a lot. It would have been very embarrassing if it had run as it was handed the first day on the story. But again this is not a success in this job.

We love it when we get to put in sentences of our own or paragraphs or things that we do editorially.

Closely related to these examples, fact checkers' descriptions of their work often focused on the ways the job helped them to build their skills and would be beneficial for their future: "It's a great way to find out how publishing works. You see it all from your desk. If you want to know what goes into it. It's a great learning."

Additionally, they boosted their self-importance by stressing the importance of fact checking to the magazine and to the industry:

I think that what we do...can be seen as in the public interest. That's something that keeps me going whether it's something that is utterly superfluous or something deadly serious, I think a reader has a right and we have a responsibility. And to be able to assure that right of the reader and the responsibility is satisfying.

Similarly, they emphasized their own "above and beyond" contributions, consistently. Officially, the fact checker's job does not begin until after an article is written. Still, several fact checkers reported doing original research and other tasks beyond those officially in the job - writing short articles, doing original research, writing captions and coverlines. Their descriptions of these episodes typically include statements about how much they enjoy doing this extra work as illustrated in Table 3.

What was perhaps the most consistently offered gloss was not intrinsic to the work itself, but rather reflected the glamour associated with working for the magazine:

I had been in Europe for so long I was out of the loop as far as what was happening in the U.S. or New York and saw Prestige magazine a couple of times and I thought it was intriguing and thought wow what an interesting magazine wouldn't it be great to work for them fantasy wise ... I thought man I'm incredibly lucky. So what appealed to me first about it was that I was working for Prestige and then gradually... what was exciting was the fact that you get to work with such great writers, such great editors.

\section{Accounts, Justification, and Disengagement}

The final category of presentations to the confidant involved how the checkers related to the job and the extent to which they defined themselves in terms of it. Most fact checkers distanced themselves from fact checking by describing intentions to leave, by claiming that they are doing the job for reasons unrelated to the intrinsic qualities of the work, and by talking about other professional identities that they hold. These descriptions seemed to offer further acknowledgement that aspects of the job were bad, so bad, in fact, that they needed to step away from it.

Nearly every fact checker interviewed expressed the intention to leave fact checking if not the entire magazine industry. For instance, one suggested he would: "like an entrée out of it." Some had timelines 
and specific exit strategies. Others had only vague notions about moving on. The desirability of leaving was also expressed in checkers' responses to questions about career successes, as in this quotation which came in response to a question about what successful fact checkers do: "Getting out of fact checking. Becoming a reporter or a writer or an editor." Additional examples of distancing, justifications, and disengagement are offered in Table 4.

\section{TABLE 4 ACCOUNTS, JUSTIFICATION, AND DISENGAGEMENT}

\begin{tabular}{|c|}
\hline \\
\hline $\begin{array}{l}\text { If you're asking me, yes. I do not want to be doing this as a career. } \\
\text { I certainly don't think I'll do it for more than five years unless they restructure the magazine to } \\
\text { make it reporter/researcher type work. } \\
\text { [Interviewer:] How long will you be here? [Fact Checker:] A year and a half to two. } \\
\text { [Interviewer:] How long will you be here? [Fact Checker:] I want this to be my last year. } \\
\text { [Martha] should only sell her screenplay. [Stuart] should only be the editor of Premier magazine. } \\
\text { [Amy] should be writing investigative pieces for the Washington Post swat teams. Or the best thing } \\
\text { that could happen to a fact checker is that they would be respected by the writers and editors and } \\
\text { paid accordingly. Because the intellectual level that is required to do this properly at this magazine is } \\
\text { far greater than the monetary reward. } \\
\text { They will leave journalism which is what they wanted to do because they just do it for a little while } \\
\text { and they go to graduate school and become something else. [Mary] did that. [Sharon Fried] did that. } \\
\text { There are a number of other people who do it. }\end{array}$ \\
\hline \\
\hline $\begin{array}{l}\text { The one coming closer to... my reason is that coming out of college...having done liberal arts sort } \\
\text { of stuff, not wanting to make or do a business or something that has structure doesn't say law } \\
\text { necessarily, wanting to work with the written word, where do you go? } \\
\text { When I moved out here, I took a loan to move out here and I was getting down to little money in the } \\
\text { checking account and it literally was on Monday I was going to go to see if I could be a bicycle } \\
\text { messenger. } \\
\text { I wanted to get out of it and I made a bad real estate investment and I had to make some money and } \\
\text { for now this is what I have to do. } \\
\text { I have the feeling that I will probably end up finding a job that paid a whole lot less at some } \\
\text { newspaper. I would probably do a whole lot more that was actually writing but I'd earn a lot less } \\
\text { money. So my job is important in so far as I'm paid a lot for what I might not be paid a lot } \\
\text { for elsewhere. }\end{array}$ \\
\hline \\
\hline $\begin{array}{l}\text { I think usually by accident. } \\
\text { I think almost all the time by accident } \\
\text { I'd never really heard about fact checking or until I read this book, Bright Lights Big City, which is } \\
\text { not directly how I became but I read this book when I was in Paris and a friend of mine who was there } \\
\text { who sort of been in New York said it was the hottest book in New York and it was great. 'You should } \\
\text { read it, you'll like it,' cause I had been planning on perhaps moving back to New York having } \\
\text { been away so long. So I read it and I said 'Wow, that looks like an interesting job ' } \\
\text { I think--how do people become fact checkers--I highly doubt that it is anyone's aspiration, really at } \\
\text { any time in their life to pursue this and to pursue and perfect this. } \\
\text { They tend to fall into it from that direction. Not by accident cause there's an interest in magazine } \\
\text { work or newspaper work or whatever. }\end{array}$ \\
\hline
\end{tabular}


I don't want to say I did it by default. It's a job and it was a way into the magazine. And it's work.

Well in my case, I started fact checking at [another] magazine cause my wife started off there as a writer and editorial assistant.

Because I didn't know what in the hell I wanted to do. I'd never heard of the job until I read Bright Lights, Big City.

Distancing themselves from the work did not always involve literal exit from the job. Checkers also separated themselves from the job through various justifications, such as being in it only for the money: "It's a way to pay your bills..., however crass that sounds. It's an epiphany that everyone goes through. You say, 'You know I can deal with this. It pays my bills. It's just a job."'

Altogether, these presentations to the confidant, as an audience, comprised a full array of aspects of the work, including explicit and matter-of-fact discussion of the negative realities of the work, extensive, albeit more cognitively effortful, highlights of the positive aspects of the work, and clear and consistent distancing of the work from checkers' sense of self. Where we expected to find efforts to reconcile or otherwise find balance between the positive and negative identities associated with Glossy Work, we did not. Nor did we find that those engaged in Glossy Work offered only enhancing descriptions of their work. Instead, fact checkers seemed to simultaneously hold both the positive and negative identities associated with their job at once. Indeed, they did not demonstrate achievement of, nor even the desire for, congruence among the differently valenced aspects of the job, as balance and dissonance theories would suggest (Festinger, 1957; Heider, 1958). Nor did they seem particularly upset or stressed about the conflict they embodied. Rather, they exhibited a sort of equilibrium from accepting both the positives and the negatives of the job.

Our observations related to presentation, however, are very different when we turn to the semi-insider and outsider audiences.

\section{Presentations to Semi-Insiders}

In all interviews, fact checkers described presentations they made to writers as an audience. Writers knew who fact checkers were and what their high level responsibilities were - to verify the information presented in the article. Writers' understanding of the fact checkers job, however, was often partial. They were not always aware of exactly what it entailed. Nor did they always understand when or why the function was required. Writers were thus semi-insiders. They were not totally in the dark about fact checking, but they were also not fully aware of what it involved.

Further, the nature of fact checkers' relationship to writers was different from that with members of other audiences. Writers and checkers worked together on an ongoing basis and the checkers' ability to do their job well was contingent on gaining and maintaining the writers' cooperation. Writers were higher status than fact checkers in these settings. Their names were higher up on magazine mastheads. They were more highly remunerated. Their renown was a basis for the magazines' renown. This combination of factors put the checkers in a one-down position in these interactions from the start.

Characterizations of the interaction between checkers and writers consistently portrayed the arduous nature of the relationship. Even writers who understood the checking process sometimes resisted it. In their presentations to the confidant they often cited the relationship with writers as one of the biggest challenges that they faced. Many fact checkers described the writers as unprofessional and temperamental. One described a particular writer as being like a "washing machine stuck on spin cycle." Others described unpleasant interactions with very well-known writers:

He has a thing about fact checkers which sometimes happens with writers. I think that there's this sense, this kind of insecurity, cause they feel challenged all the time. And they feel as though they are being undermined and you often hear writers, especially if the relationship is not going that well, complaining about that, feeling as though they're being picky and they're not. 
Then I called him up with a decent chunk of questions just because there were things that were wrong and I brought up something in the first line, something in the second line, then once we got to the third line, the third thing I had to check, his quote was, "Jesus Christ. All fucking mighty. We're in the third line. Everything's wrong. It's all wrong isn't it? I have no fucking time to do this and it's completely ridiculous. It's just a little piece of fluff. Don't bother me with this." And I said to him, "Fluff or not. If it's fluff, it has to be accurate fluff." And that's it.

Much of fact checkers presentation of themselves to the writers came as they tried to persuade the writers to cooperate with them: to provide research materials or to make changes. As noted, the fact checkers have little formal authority or power over the writers. Even so, several described occasions where they did establish forms of authority in presenting themselves to writers. For instance, one described an introductory conversation with a writer where she informed the writer that his story could not close without fact checker approval:

I had an experience several months ago where I was speaking with a writer who had never written for us before and worked principally in broadcast and also covered matters of national security and was very, very suspicious of the fact that he would have to release his notes to us and, in one sense, that was good because a writer who respects his sources and wants to honor confidentiality agreements is certainly the kind of writer we want to deal with. He's a responsible journalist. In another sense, for us to be responsible journalists in our role as intermediary and also in our role in protecting the magazine from inaccuracy and from legal suits. It took me a very long time to convince this man that he would have to do this and finally he said, "What if I don't." And I said, "Essentially, if research doesn't sign off on your article, it can't be published." There was a pause and he said, "What's your FedEx number?"

Many checkers described making it clear to writers that in certain circumstances - most often when there are legal issues involved - they had little choice but to comply with them, as in the following quotations:

[Interviewer:] What are the sort of things you say to him to get him to take your changes? [Fact checker:] I have to employ a lot of silence while he goes on. Then I say, "[Mike] well you just have to." First of all, I use the lawyers excuse. Then he gets more freaked out when I talk about lawyers so I try to avoid that. And I just pretty much give it to him straight-forward. I don't even need to--I don't even explain to him. I say, "This needs to change."

Well, I always preface, especially with a first time person with the magazine--it's easier if they've done it here before and know what the process is--I always emphasize that they are legally obligated cause that usually shuts them up.

In making presentations to writers fact checkers often brought in various personal characteristics to distance impressions from the taint or the role and build their personal credibility. For instance, when working on an article about the former Soviet Union, one fact checker described making certain that the writer knew that he spoke Russian:

I think also because I was Russian and spoke some Russian he felt I knew what I was talking about. He was a little more passive and a little more respectful.... Well first my name is Russian. So that was a start. So he sort of asked about it directly. And then there was some research he had in Russian and I said that's no problem, cause I can read it. 
Similarly, others described conveying specific expertise garnered through the process of checking. One checker described how she went about checking the work of one particularly difficult and famous writer:

The way you check [writer's name] is you find out how she's wrong and then you have to call not one but several people, and you also have to know that they are people who she respects. You have to get the three of them all to conclusively disprove what she has written and to provide a fix that is elegant. And then what I usually do is write in the fix, get confirmation from several - it's usually at least three before she'll listen to me - and tell her what it should be and who it is who says that she is wrong and then she accepts it. But she will sometimes change the wording a little.

Others described similar incidents of bringing in their evidence:

You present them with the facts and you tell them where the numbers come from. "Five thousand people did not die in Germany from fire bombings. Five did. This is from blah blah blah blah source." And she'll back down usually.

You have to supply her with an overwhelming amount of evidence that what she's written is either wrong or just misinterpreted because considering it's about [an actor] who she has a bond with and she thinks she has more of a perspective on so then it's just gaining as much evidence as you can to present to her.

While each checker had distinct ways of presenting themselves to the writers, several common practices emerged: gathering information about the writer, developing and communicating expertise on the story subject matter; being polite and even obsequious with writers; not telling writers that they are wrong; aligning themselves with writers; providing fixes for any problems identified; and being selective about which battles to fight and when to bring in allies, as described in Table 5.

\section{TABLE 5}

\section{PRESENTATIONS TO WRITERS}

\section{Gather information about the writer}

I was warned by a lot of people how difficult he was to work with

I think that when somebody is new--I was just told that I'm going to do a piece with [well-known writer] and everyone gave me his two cents on [that writer] and what that's all about, etc., etc. And I did a piece with [another well-known writer] and everyone had their [writer] story

That's another standard that you use. If you're checking someone for the first time, you ask around. You know, "Who is this guy?" Or the head of fact checking will say, "Watch out. We've had problems with this person."

I asked people who had worked on her previous piece what problems they had had with her so I could try to anticipate. She had done one piece previously [for the magazine]. The researcher had had some problems with it. She tended - this writer tended to be a little disconnected and you had to sort of pull her back in

If you're unfamiliar with the person you're going to be slamming your foot in the door constantly until you've got it figured out. You try to figure out very quickly what buttons to push to get them to help and not be a hindrance, to get them to call people, to get them to sit down to listen to the things you're going to ask. I suppose day in and day out that would be the most difficult thing: the personalities you have to deal with in trying to figure out. You didn't have time to be a psychiatrist or a psychologist and try to figure out their take on everything was. 


\section{Never tell them they are wrong}

I never ever tell a writer, "You're wrong." Because that makes them automatically defensive which you never want to do cause they are difficult enough to deal with especially if they think you're changing their story

She would say, "Well, I got it from so and so." I would say, "Well we called someone else at Sony and this is what they told us. Do you think someone is putting spin on it." So I would try to get her idea on it rather than straight-out accuse someone of being wrong or saying, "I think we have to change this.

I say, "I want to go over your piece." I try not to say "go over changes" cause that really sets off the wrong thing. It means I've made changes when reality is I'm just going over approval. So I just say, "I want to check some things with you and make sure what I have is correct." It's basically what I say to sources. I say, "I want to make sure the writer has this correct." I say, "I just want to make sure what I have is correct. I have conflicting information."

You know, "You say this happened a week later but actually it happened three days later." And again you're trying to say it in a way where you're not saying, "Well this happened three days later."

In any case, what I would do is I would talk to Allman about it and if he resists, I would say, "Can't we say it another way." I would try to suggest other ways of dealing with it. And that's what I mean about the reporting. Cause usually that's a discussion the writer is more comfortable with than if you're just telling him, "You can't do this."

\section{Align self with writer}

Anne does not let a writer get away with anything, but at the same time has great sympathy for the writer so can balance respect for the writer and empathy for the writer as well as remaining rigorous in the service of the magazine.

I think other times, a writer will take a change if you make it clear that they will seem stupid if they don't. They don't want to look stupid.

I tend to sympathize with the writers who complain about meaningless pickyness. I've seen fact checkers kind of aggression about tearing down pieces with a writer which I think is counter productive.

Yes. I think it also helps if you to deal with a piece to a certain degree as a reporter. When I said before to look at it from the perspective of a writer you should say reporter. Cause if you're trying to collect information or to sift through information with them rather than just decide if it's right or wrong that makes it a really big difference.

\section{Be polite}

We remain polite. It's the writers who go out of control.

With other writers [I'll be] obsequious and let them know that they are king and that they will be the almighty writer.

We have a very congenial relationship... where I'm coddling him but it's a very manipulative sort of thing.

And I said, "There were a couple things that I wanted to go over with you." That's standard procedure. Going over with you means essentially--it's the general euphemistic way of saying, as I'm sure you know, "We have to go to work on this." And then he said, "OK." And I said, "First, second, third, etc."

I perceive myself to be overly diplomatic. I will put off, soften. I will wait. I'm non-confrontational.

\section{Offer them solutions}

Something I've been told by the editors is "Don't tell me if it is wrong. Give me a fix.

One of the things that really bothered him [an editor and writer] about researchers was that they would destroy a fact without replacing it so that you're telling him this is wrong. This doesn't work. 
And he's like, "Great, I need a fact. You've just destroyed this one. Couldn't you have asked the person while you had him on the phone for another response." If you get involved with the reporting aspects of it, at least in the discussion, I think it makes things run a lot smoother. And the writer feels much more supported.

If he resists, I would say, "Can't we say it another way." I would try to suggest other ways of dealing with it.

The best fact checkers, if they find a problem will have a solution in hand. Or an alternate wording or an acceptable solution. Or additional information to pop in. So you're not just presenting a problem, you're presenting a potential solution or some kind of wording that the author or writer can play witty in their mind to come up with a phrase they like that everyone can live.

\section{Choosing your battles}

I would bring it up again to the writer or the editor. I would make sure I bring it up more than once. And if they refuse it both times, I would say, "OK. It's on you." Then I'd make sure in my margins that I did approach this, but I don't have a tizzy over it. I let it go. It's not my problem.

You have to realize which battles to win and which battles to ignore.

Discretion is the better part of valor. I thought, "I'm curious to know, but it's not my place to ask." So I didn't.

It's a hard lesson to learn but you really have to pick your battles and know when to cut your losses and when to go after something and when to just say, "All right give up."

There are other editors who if--and it comes to picking your battles--if you want to make a change where they don't think it's a problem of research where they think it's style, or copy, or editorial, they will get angry. If you're making changes that they don't think are worthwhile and you're making a lot of them they will get angry.

I never asked her about that because that would have caused problems. Discretion is the better part of valor. I thought, "I'm curious to know, but it's not my place to ask." So I didn't.

\section{Selectively bring in allies}

And I hung up on her. And I went to [the editor], a very sweet guy who is the editor on this, and I said, "I'm not dealing with her. I think maybe you want to have a talk with her." All I know is that she called me back twenty minutes later apologetic and things were better from that point on. When I say better, it still was never good.

Then of course, you build these alliances and you'll go to [the legal editor] and he'll say, "Well that's idiotic. You can't say that. Maybe we can say it. Maybe we can't. Maybe we should say, 'alleged."' Then you come back to him and say, "Robert said this. I think this. What do you think?"

Some editors are very approachable and you can work long and hard with them. [Mark] for example. I would have no problem working with him for hours. Sometimes we would just end around the wrier completely....If we determined that the writer just wasn't at home, ...we just took the writer out of the loop cause we didn't have time.

But like this piece on skinheads. I was on the phone with her at two in the morning the night it was closing with the head of copy editing, the editor and the lawyer and we were passing the phone around, all trying to talk her out of things. With a writer with her reputation you can argue. With a writer with a lesser reputation you would just go to the editor and the editor would cross it out.

Overall, these presentations were more personal in nature than those made to the confidant, that is, they reflected the checkers relying less on their formal role and more on general social and interpersonal skills to present themselves to the writers. 


\section{The True Outsiders}

In contrast to the presentations made to the confidant and to the writers, presentations to true outsiders - who could easily see the Glossy aspects of the job but not the details underneath - were the narrowest in scope and seemingly the simplest in terms of likely motivation. Presentations to outsiders were consistently enhanced, by either enhancing the job itself or by mixing Glossy elements of the job into the presentation. Whether they chose to reveal the realities of their job title and all that it implies seemed to rest on the level of investment they had in the audience's opinion of them, as explained here:

It depends on the person. If I had absolutely nothing invested in the person: "I'm a fact checker at [Elite]." And then you get the standard questions about [Elite] because you're affiliated with the magazine people think you're a strange type of royalty no matter how you're affiliated. And if it was someone I was interested in a little bit more on whatever level, I would say that I write, that I'd like to be a writer.

One presentation strategy, for audiences in whom the fact checkers had some investment or whose opinion matters to them, was to make other professional roles or ambitions more salient than the fact checker job in the presentation of their work. Checkers would invoke broader, more elevated roles as their profession, presenting their job as writing or a part of journalism more broadly, clearly and deliberately enhancing the presentation. For example:

Cause like yesterday I went to MoMA to interview the curator of architecture for a piece I was doing and I certainly did not tell him I was a fact checker. I presented myself as a writer.

I never say "fact checker." I say I work in the research department. That sounds more elevated. People who don't know publishing are absolutely floored and want to know more. People do usually move on.

[Interviewer:] If someone at a party asked you what you did, how would you answer? [Fact checker:] A writer.

Generally say I'm in the research department at [Prestige] and I write some [short] pieces. If we go into a little bit more I tell them that I'm also a screenwriter.

What was most conspicuous across the presentations made to outsiders was the total absence of disclosure of the negative realities of the job. Fact checkers seemed to be aware of how revealing the secret of their job - that they were actually low status fact checkers - could denigrate others' impressions of them. The matter-of-fact acceptance, and open discussion, of the challenges of the job that flowed so freely to the confidant never surfaced in checkers' descriptions of the presentations to outsiders. This audience saw only one side of the job, when they were presented with the actual job at all. The focus of the fact checker performance to this audience seemed to be in keeping the negative aspects of the job under wraps, keeping the secret a secret.

\section{DISCUSSION}

We began this paper by introducing Glossy Work - work that on the surface looks glamorous but that below that surface is far less desirable - as a distinct type of work. We asked a set of questions about how those engaged in such work incorporate these positive and negative aspects into their presentation of their job and how these presentations varied across audiences. We examined this among a set of fact checkers at glossy magazines, whose jobs typify Glossy Work. In order to gain insight into these issues, we took advantage of an unconventional methodology: having an insider - a former fact checker - conduct the 
interviews. The interviewer played the role of confidant and this allowed us potentially to hear a fuller range of the presentations made by fact checkers.

We expected motivations around self-enhancement and self-verification to be the primary contingencies determining how the job was presented to different audiences, with positive aspects of the job presented to audiences who did not know the job's dirty secret and negative aspects of the job emphasized to those who did. We further expected fact checkers to demonstrate efforts to reconcile or find balance among the discrepant aspects of their job through presentations to others. What we found was a more nuanced and complex model of presentation that did include what looked like very straightforward applications of enhancement and verification motives but also conveyed presentations to one audience that mixed these motives with surprising ease, more subtle and behavioral presentations to another couched in framing a personal rather than role-based performance, and an unexpected level of acceptance of the job's inherent incongruence.

Specifically, Glossy Workers framed their presentation of the work conditionally, according to their audience's knowledge of the realities of the job and to the nature of the checker's relationship to the audience. With insiders, there is less opportunity to distort the truth and little incentive to abide the anxieties that hiding the truth can elicit (Schlenker \& Leary, 1982). Thus checkers did not try to cover up the negative realities of the job to their insider audiences - the confidant and the writers. However, their presentations to these two audiences differed greatly. Checkers seemed almost blasé about the realities of the job with the confidant, including them in their presentations in a matter-of-fact, open, easy tone. They sought neither pity nor empathy from the confidant, an audience with whom they expected no future interaction, and instead seemed to just report the facts as facts.

Writers were a very different audience, however. They were somewhat knowledgeable about the actual tasks fact checkers perform and therefore could not be entirely fooled about the realities of the job; they also enjoyed high status over fact checkers, who needed writers' cooperation to complete their job tasks. The interaction with this audience was ongoing, with a high level of interdependence. With the writers, fact checkers worked hard to manage the implications of the downsides of their job. They wanted to be perceived by the writers as professional and constructive, and so they presented themselves to this audience largely in that fashion (Markus \& Nurius, 1986). Checkers worked to combat the negative image of the job in their presentation to writers with careful and deliberate interactions, aimed at shifting away from the role-based image of checker and toward a more interpersonal connection.

Presentations to both of these audiences stand in contrast to how checkers presented their work to outsiders, where unfettered enhancement of the job or of the self, in various ways, shaped what was conveyed.

These presentations all reached a fourth and crucial audience: the self. Ultimately all presentations are presentations to the self. A review of fact checkers' presentations to different audiences and the effects of those presentations begs the question of how checkers themselves took in their own presentations. None of those interviewed were able to fully counteract the negatives and fully embrace the job. Indeed, despite the elevated presentations, every checker maintained a negative perspective of the job, as summed in the following quotation:

And you know, every fact checker I know regards it, often hates it, and thinks that it is a
waste of their time and abilities. There's this sense that, "Oh, God. How long am I going
to be fact checking?" ... I joke with my friends sometimes about why I hate fact checking
at [Elite]. I say, "It's because they have stolen my youth." ... I've been there a long time
and I'm not really going anywhere.

This suggests that the fact checkers are not entirely taken in by their own presentations (Goffman, 1956). They may be able to spin a nice story about their job while still believing the job is not nice.

Across audiences, it was notable that constructing the positive descriptions usually entailed more labor, whereas the negative descriptions were more plainly factual. To present many of the "positive" aspects of the job as positive, fact checkers had to use both cognitive and behavioral energy to frame the 
job. Their motivation to undertake this labor of reframing the job may reflect an unwillingness to tolerate the job as wholly negative. The enhancement motivation to improve one's condition is universal and is reflected here, even where it meant enduring incongruence within the self. Where Glossy Work seems to differ from other types of potentially unsatisfying work is that the negative aspects were not neutralized by enhanced descriptions of the job.

In fact, it was rather striking how comfortably fact checkers held on to the discrepant aspects of the job in their presentations to the confidant. One might expect, to an audience who really understood the harsh realities of the job, fact checkers would only talk negatively. The confidant offered an opportunity to seek verification and to simplify the contradictions inherent in the job by admitting the overall negative flavor. However, contrary to theories of dissonance and balance (Festinger, 1954; Heider, 1958), every fact checker presented both the positive and negative. Perhaps, in some way, since the negative were unavoidable and the positive were available, fact checkers embraced the incongruence and coped with it by seeking verification from the confidant of the incongruence itself rather than of either the positive or negative aspects of the job alone.

Our findings provide several additional points of contrast to previous literature that discusses how people cope with unsatisfactory jobs. We do see people engaged in many of the identity preserving strategies described in literatures on Dirty Work (Ashforth \& Kreiner, 1999; Ashforth, et al., 2007), job crafting (Berg, Grant, et al., 2010; Berg, Wrzesniewski, \& Dutton, 2010; Wrzesniewski \& Dutton, 2001), and social identity more generally (Tajfel \& Turner, 1986). Yet, we see significant differences in the overall patterns. Unlike Dirty Work, fact checkers do not fully embrace their work. Unlike generally low status job-holders, fact checkers do not simply re-categorize themselves on a more positive aspect of their job (Turner, 1987). Unlike job crafters, they do not make lasting changes to the job even though they engage in some provisional cognitive and task boundary manipulations that closely parallel those described in crafting (Berg, Grant, et al., 2010; Berg, Wrzesniewski, et al., 2010; Wrzesniewski \& Dutton, 2001). Similarly, though they do many of the activities that others do to maintain dignity at work (Hodson, 2001), they do not seem to end up feeling very dignified. The most significant difference we see, however, is that these Glossy Workers are unable to create a positive identity. Perhaps the closest parallel is the one to Roy's workers who in Banana Time are entertained for a period but in the end have to do their same boring jobs (Roy, 1959).

The specifics of the descriptions offered by fact checkers are unlikely to be repeated by other groups. Others may not be able to make the same claims of status related to working in high status organizations. Nor will they necessarily have opportunities to add tasks to their work. However, there is reason to believe that those engaged in other forms of Glossy Work will display the same tendencies in their descriptions. Beyond work that fits the definition of Glossy Work, similar behaviors might also be observed among those who have high status jobs that are made up of low-status tasks: bankers who spend their days formatting spreadsheets and professors who spend hours coding data. Future work might explore this question.

\section{REFERENCES}

Allport, G. W. (1937). Personality: A Psychological Interpretation. New York: Henry Holt.

Anteby, M. (2013). Relaxing the taboo on telling our own stories: Upholding professional distance and personal involvement. Organization Science, 24(4), 1277-1290.

Arkin, R. M., \& Shepperd, J. A. (1990). Strategic self-presentation: An overview. The psychology of tactical communication, 175-193.

Ashforth, B. E. (2001). Role Transitions in Organizational Life: An Identity-Based Perspective. Mahwah, New Jersey: Routledge.

Ashforth, B. E., \& Kreiner, G. E. (1999). "How can you do it?” Dirty work and the challenge of constructing a positive identity. Academy of Management Review, 24(3), 413-434.

Ashforth, B. E., Kreiner, G. E., Clark, M. A., \& Fugate, M. (2007). Normalizing dirty work: Managerial tactics for countering occupational taint. Academy of Management Journal, 50(1). 
Ashforth, B. E., \& Mael, F. (1989). Social identity theory and the organization. The Academy of Management Review, 14(1), 20-39. doi: 10.2307/258189

Baumeister, R. F. (1982). A self-presentational view of social phenomena. Psychological Bulletin, 91(1), 3.

Berg, J. M., Grant, A. M., \& Johnson, V. (2010). When callings are calling: Crafting work and leisure in pursuit of unanswered occupational callings. Organization Science, 21(5), 973-994.

Berg, J. M., Wrzesniewski, A., \& Dutton, J. E. (2010). Perceiving and responding to challenges in job crafting at different ranks: when proactivity requires adaptivity. Journal of Organizational Behavior, 31(2-3), 158-186. doi: Doi 10.1002/Job.645

Bunderson, J. S., \& Thompson, J. A. (2009). The call of the wild: Zookeepers, callings, and the doubleedged sword of deeply meaningful work. Administrative Science Quarterly, 54, 32-57.

Cohen, L. E., \& Staw, B. M. (1998). "Fun's over. Fact checkers are here": A case study of institutionalized dissent in the magazine publishing industry. Advances in Qualitative Orgnaizational Research, 1, 100-135.

Crowne, D. P., \& Marlowe, D. (1964). The approval motive: Studies in evaluative dependence: Wiley New York.

Church, A., Katigbak, M., Ibañez-Reyes, J., Vargas-Flores, J., Curtis, G., Tanaka-Matsumi, J., ... Simon, J-Y. (2014). Relating Self-Concept Consistency to Hedonic and Eudaimonic Well-Being in Eight Cultures. Journal of Cross-Cultural Pscyhology, 45(5), 695-712. https://doi.org/10.1177/0022022114527347

Dick, P. (2005). Dirty work designations: How police officers account for their use of coercive force. Human Relations, 58(11), 1363-1390.

Dunham, H. W., Phillilps, P., \& Srinivasan, B. (1966). A research note on diagnosed mental illness and social class. American Sociological Review, 31, 223-227.

Dutton, J. E., Dukerich, J. M., \& Harquail, C. V. (1994). Organizational images and member identification. Administrative Science Quarterly, 239-263.

Edmondson, A. C., \& McManus, S. E. (2007). Methodological fit in management field research. Academy of Management Review, 32(4), 1155-1179.

Elias, N. (1956). Problems of involvement and detachment. The British Journal of Sociology, 7(3), 226252.

Elsbach, K. D., \& Bhattacharya, C. (2001). Defining who you are by what you're not: Organizational disidentification and the National Rifle Association. Organization Science, 12(4), 393-413.

Elsbach, K. D., \& Flynn, F. J. (2013). Creative Collaboration and the Self-Concept: A Study of Toy Designers. Journal of Management Studies, 50(4), 515-544.

Fenchel, G. H., Monderer, J. H., \& Hartley, E. L. (1951). Subjective status and the equilibration hypothesis. Journal of Abnormal and Social Psychology, 46(4), 476.

Festinger, L. (1954). A theory of social comparison processes. Human Relations, 7(2), 117-140.

Festinger, L. (1957). A cognitive theory of dissonance. Row Petersen, Evanston, IL.

Fine, G. A. (1996). Justifying work: Occupational rhetorics as resources in restaurant kitchens. Administrative Science Quarterly, 41.

Goffman, E. (1956). The Presentation of Self in Everyday Life. Edinburgh: University of Edinburgh Social Sciences Reserach Centre.

Goffman, E. (1967). Interaction Rituals. Garden City, NY: Anchor.

Gold, R. (1952). Janitors versus tenants: A status-income dilemma. American Journal of Sociology, 486493.

Hackman, J. R., \& Oldham, G. R. (1975). Development of the job diagnostic survey. Journal of Applied Psychology, 60, 159-170.

Heider, F. (1958). The psychology of interpersonal relations: Psychology Press.

Hodson, R. (2001). Dignity at work: Cambridge University Press.

Honjo, D., Iso, H., Inoue, M., Sawada, N., \& Tsugane, S. (2014). Socioeconomic Status Inconsistency and Risk of Stroke Among Japanese Middle-Aged Women. Stroke, 45(9), 2582-2598. 
Hughes, E. C. (1958). Men and their Work. New York Free Press.

Hughes, E. C. (1962). Good people and dirty work. Social Problems, 10(1), 3-11.

Ibarra, H., \& Barbulescu, R. (2010). Identity as narrative: Prevalence, effectiveness, and consequences of narrative identity work in macro work role transitions. Academy of Management Review, 35(1), $135-154$.

Jackson, E. F. (1962). Status consistency and symptoms of stress. American Sociological Review, 27, 469-480.

Mael, F., \& Ashforth, B. E. (1992). Alumni and their alma mater: A partial test of the reformulated model of organizational identification. Journal of Organizational Behavior, 13(2), 103-123. doi: $10.1002 /$ job.4030130202

McGregor J. (2017) Re-envisioning the Dignity of Women's Work. In: Sieh E., McGregor J. (eds) Human Dignity. Palgrave Macmillan, London

Meyerson, D. (2001). Tempered Radicals: How People Use Difference to Inspire Change at Work. Boston: Harvard Business Press.

Milner, A., Aitken, Z., Kavanagh, A., LaMontagne, A., \& Petrie, D. (2017) Status inconsistency and mental health: A random effects and instrumental variables analysis using 14 annual waves of cohort data. Social Science \& Medicine, 189(129-137).

Peterson, R. A. (2005). In Search of Authenticity. Journal of Management Studies, 42(5), 1083-1098.

Roberts, L. M. (2005). Changing faces: Professional image construction in diverse organizational settings. Academy of Management Review, 30(4), 685-711.

Roy, D. F. (1952). Quota restriction and goldbricking in a machine shop. American Journal of Sociology, $57(5), 427-442$.

Roy, D. F. (1959). Banana time: Job satisfaction and informal interaction. Human Organization, 18, 158168.

Schlenker, B. R. (1975). Self-presentation: managing the impression of consistency when reality interferes with self-enhancement. Journal of Personality and Social Psychology, 32(6), 1030.

Schlenker, B. R. (2003). Self-presentation.

Schlenker, B. R., \& Leary, M. R. (1982). Audiences' reactions to self-enhancing, self-denigrating, and accurate self-presentations. Journal of experimental Social Psychology, 18(1), 89-104.

Starr, P. D. (1977). Marginality, role conflict, and status inconsistency as forms of stressful interaction. Human Relations, 30(10), 949-961.

Swann, W. B. (1983). Self-verification: Bringing social reality into harmony with the self. Social Psychological Perspectives on the Self, 2, 33-66.

Swann, W. B. (1990). To be adored or to be known : The interplay of self-enhancement and selfverification. In R. M. Sorrentino \& T. Higgins (Eds.), Foundations of Social Behavior (Vol. 2, pp. 408-448). New York: Guilford.

Swann, W. B., Pelham, B. W., \& Krull, D. S. (1989). Agreeable fancy or disagreeable truth? Reconciling self-enhancement and self-verification. Journal of Personality and Social Psychology, 57(5), 782791.

Tajfel, H., \& Turner, J. C. (1986). The social identity theory of intergroup behaviour. In S. Worchel \& W. G. Austin (Eds.), Psychology of Intergroup Relations. Chicago: Nelson-Hall.

Taylor, S. E., \& Brown, J. D. (1988). Illusion and well-being: A social psychological perspective on mental health. Psychological Bulletin, 103(2), 193.

Tesser, A. (1988). Toward a self-evaluation maintenance model of social behavior. Advances in Experimental Social Psychology, 21, 181-228.

Treiman, D. J. (1977). Occupational Prestige in Comparative Perspective. New York: Academic.

Van Yperen, N., Wörtler, B., \& De Jonge, K. (2016) Workers' intrinsic work motivation when job demands are high: The role of need for autonomy and perceived opportunity for blended working. Computers in Human Behavior, 60, 179-184.

102 Journal of Organizational Psychology Vol. 20(1) 2020 
Vough, H. C., Cardador, M. T., Bednar, J. S., Dane, E., \& Pratt, M. G. (2013). What clients don't get about my profession: A model of perceived role-based image discrepancies. Academy of Management Journal, 56(4), 1050-1080.

White, K, Stackhouse, M., \& Argo, J. (2018). When social identity threat leads to the selection of identity-reinforcing options: The role of public self-awareness. Organizational Behavior and Human Decision Processes, 144, 60-73. https://doi.org/10.1016/j.obhdp.2017.09.007

Wrzesniewski, A., \& Dutton, J. E. (2001). Crafting a job: Revisioning employees as active crafters of their work. Academy of Management Review, 26(2), 179-201.

Wrzesniewski, A., McCauley, C., Rozin, P., \& Schwartz, B. (1997). Jobs, careers, and callings: People's relations to their work. Journal of Research in Personality, 31(1), 21-33. 